\title{
Prevalence of type 2 diabetes in the Islamic Republic of Iran: systematic review and meta-analysis
}

A.A Haghdoost, ${ }^{1,2}$ M. Rezazadeh-Kermani, ${ }^{1}$ B. Sadghirad ${ }^{3}$ and H.R. Baradaran ${ }^{4}$

$$
\begin{aligned}
& \text { معدَّل انتشار النَمَط } 2 \text { من السكري في جمهورية إيران الإسلامية: مراجعة منهجية وتحليل تلوي }
\end{aligned}
$$

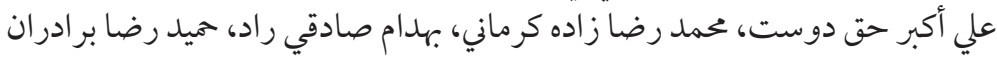

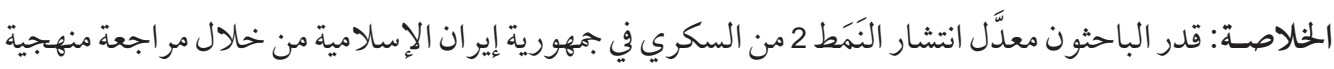

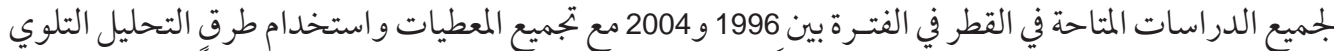

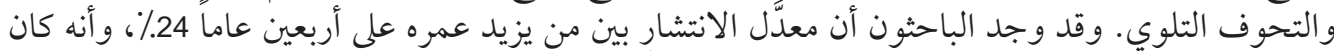

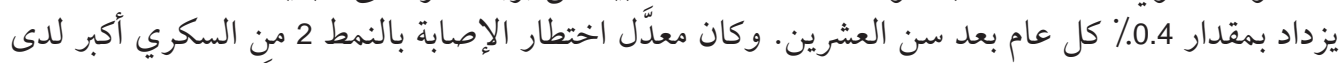

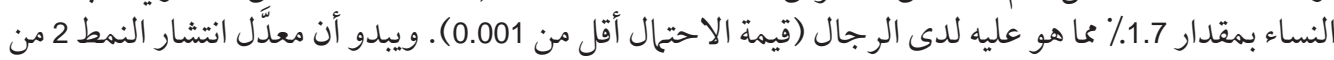

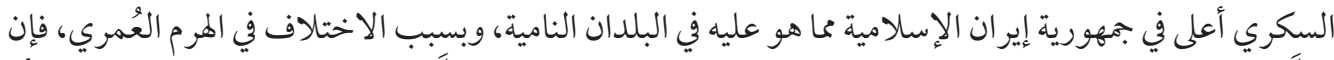

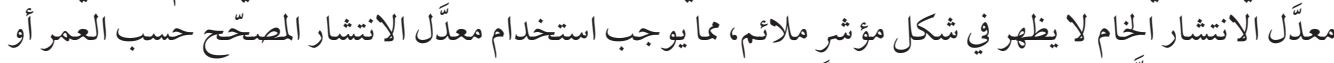

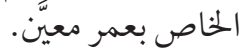

ABSTRACT We estimated the prevalence of type 2 diabetes in the Islamic Republic of Iran by systematic review of all available studies in the country between 1996 and 2004 and aggregation of the data using meta-analysis and meta-regression methods. In those $>40$ years the prevalence was $24 \%$ and it increased by $0.4 \%$ with each year after 20 years of age. The risk of type 2 diabetes was $1.7 \%$ greater in women than men $(P<0.001)$. The prevalence of type 2 diabetes appears higher in the Islamic Republic of Iran than in other developing countries but because of differences in age pyramids, the crude prevalence is not an appropriate indicator and age-adjusted or age-specific prevalences should be used.

\begin{abstract}
Prévalence du diabète de type 2 en République islamique d'Iran : étude systématique et métaanalyse

RÉSUMÉ Nous avons estimé la prévalence du diabète de type 2 en République islamique d'Iran grâce à l'analyse systématique de toutes les études disponibles dans le pays entre 1996 et 2004 et à l'agrégation des données par les méthodes de méta-analyse et de méta-régression. Chez les plus de 40 ans, la prévalence était de $24 \%$ et elle augmentait de 0,4\% par an après l'âge de 20 ans. Le risque de diabète de type 2 était supérieur de $1,7 \%$ chez les femmes que chez les hommes $(P<0,001)$. La prévalence de ce diabète semble plus élevée en République islamique d'Iran que dans les autres pays en développement, mais en raison des différences dans les pyramides des âges, la prévalence brute n'est pas un bon indicateur et il convient d'utiliser la prévalence ajustée sur l'âge ou la prévalence par âge.
\end{abstract}

${ }^{1}$ Physiology Research Centre; ${ }^{3}$ Kerman Neuroscience Research Centre, Kerman University of Medical Sciences, Kerman, Islamic Republic of Iran.

${ }^{2}$ London School of Hygiene and Tropical Medicine, London, United Kingdom.

${ }^{4}$ Institute of Endocrinology \& Metabolism, Iran University of Medical Sciences, Tehran, Islamic Republic of Iran (Correspondence to H.R. Baradaran: Baradaran@iums.ac.ir).

Received: 01/02/07; accepted: 15/05/07

المجلة الصحية لشرق المتوسط، منظمة الصحة العالمية، المجلد الخامس عشر، العلد ب، 9 +. ب 


\section{Introduction}

Type 2 diabetes mellitus is a common, costly condition associated with significant morbidity and mortality [1]. The number of people with this condition is increasing due to population growth, ageing, urbanization, and increasing prevalence of obesity and physical inactivity. Type 2 diabetes constitutes a growing global public health problem: currently about 135 million people are affected and an estimated 300 million will be affected by 2025 . This pandemic involves not only the industrialized world but also less-developed countries where urbanization and industrialization are proceeding rapidly [2]. The populations of developing countries, minority groups and disadvantaged communities in industrialized countries are now at greatest risk [3].

The Islamic Republic of Iran is one of the largest countries in the Middle East, with a population of around 70000000 . It is a heterogeneous population with many ethnic groups; Turkish in the north-west, Kurdish in the west, Arab in the south and south-west, Pars (Farsi) in the centre, Turkmen in the north-east and Baluch in the east. A number of studies with various sample sizes have estimated the prevalence of type 2 diabetes in different regions of the country. We therefore aimed to conduct a systematic review and meta-analysis of reports of the prevalence of type 2 diabetes to estimate the overall prevalence of the condition in the Islamic Republic of Iran.

\section{Methods}

\section{Search strategy}

We searched the English-language medical literature published between January 1996 and December 2005 using the Medline database of the National Library of Medicine. The medical subject headings (MeSH) we searched were "diabetes mellitus" and "hyperglycaemia" combined with "prevalence" and "Iran" including all subheadings. In addition, we searched for all abstracts, conference proceeding, titles of theses, dissertations and reports in other databases in Farsi, such as IranMedex, IranDoc, Iranian Archive for Scientific Documents Center (IASD), Iranian National Library (INL). The keywords used were the Farsi equivalent of the English.

\section{Study selection}

All studies carried out to estimate the prevalence of type 2 diabetes in the Islamic Republic of Iran between 1996 and 2005 were included. We excluded studies with fewer than 300 individuals, with non-random sampling methods and mixed type 2 and type 1 diabetes. The criteria for diagnosis of diabetes were based on those of the World Health Organization (WHO). In addition, we included the first national health survey [Iranian Health Profile Survey (IHPS)] .

\section{Data extraction}

We categorized citations based on 4 age groups: $<15$ years, $15-25,26-4$ and $>40$ years. Most of the selected studies reported the prevalence of type 2 diabetes in more than 1 age group; therefore, we entered the age-specific prevalence of these studies in our meta-analysis. In addition, the mean age of subjects, publication date, sample size classified by sex, study location and type of study (IHPS or individual) were entered in our meta-regression analysis to assess trends in the prevalence of type 2 diabetes.

\section{Statistical analysis}

The variation of prevalence of type 2 diabetes in each study was computed based on the binomial distribution formula. After using the heterogeneity test, we found significant variation between study findings, therefore 
we used a random effect model to estimate the overall prevalence. In addition, in order to minimize the random variation between point estimates of the studies, we adjusted the findings from every study using Bayesian analysis. In this adjustment, the overall point estimate based on the random effect model was used as prior prevalence. Having described the findings in forest plots, the point estimates and their $95 \%$ confidence interval (CI) were computed accordingly.

We used meta-regression to assess the effect of age, sex, type of study and publication date as possible sources of the heterogeneity among the studies' findings and to estimate the stratum-specific prevalence. We estimated tau-squared $\left(\tau^{2}\right)$ using a restricted likelihood method, as the indicator of heterogeneity. All of the analysis was done in STATA, version 8.

\section{Results}

The findings of this review are summarized in Table 1. We used the IHPS data for 27 provinces as well as 20 individual studies (17 papers, 1 unpublished research project and 2 congress proceedings) from 14 provinces across the country. Studies performed in Isfahan and Markazi provinces had the largest sample size with 12494 individuals [17] and Sabzevar district had the smallest sample with 450 subjects [11].

The overall estimates of the prevalence of type 2 diabetes based on the IHPS and the individual studies were $2.3 \%$ and $9.34 \%$ respectively (Table 2); however, the findings of the latter category had substantial heterogeneity $(P<0.001)$.

To assess the source of heterogeneity and the difference in the estimations of the

\begin{tabular}{|c|c|c|c|c|c|c|}
\hline \multirow[t]{2}{*}{ First author } & \multirow[t]{2}{*}{$\begin{array}{c}\text { Publication } \\
\text { year }\end{array}$} & \multirow[t]{2}{*}{$\begin{array}{l}\text { Sample } \\
\text { size }\end{array}$} & \multicolumn{2}{|c|}{$\begin{array}{c}\text { Criteria prevalence } \\
\text { were based on }\end{array}$} & \multirow[t]{2}{*}{$\begin{array}{c}\text { Age group } \\
\text { (years) }\end{array}$} & \multirow[t]{2}{*}{ Sex } \\
\hline & & & WHO & $A D A$ & & \\
\hline F. Sharifi [4] & 1999 & 1977 & + & - & $30-92$ & Both \\
\hline B. Larijani [5] & 2002 & 982 & + & + & $30-64$ & Both \\
\hline P. Bastanhagh [6] & 1996 & 2800 & + & - & $>30$ & Both \\
\hline E. Osfouri [7] & 1998 & 1036 & + & - & $30-64$ & Both \\
\hline F. Sajadi [8] & 2003 & 800 & + & - & $>19$ & Both \\
\hline K. Yazdanpanah [9] & 2000 & 2000 & + & - & $>10$ & Both \\
\hline M. Afkhamiardakani [10] & 2002 & 2795 & + & - & $>30$ & Both \\
\hline M. Jafarzadehfakhari [11] & 2000 & 450 & + & - & $19-80$ & Both \\
\hline F. Azizi [12] & 2003 & 1603 & + & - & $>60$ & Both \\
\hline F. Azizi [13] & 2002 & 6899 & + & - & $30-69$ & Both \\
\hline H. Fakhrzadeh [14] & 2002 & 1255 & + & - & $>30$ & Male \\
\hline B. Larijani [15] & 2003 & 950 & + & + & $>25$ & Both \\
\hline Z. Salem [16] & 2003 & 756 & + & + & $>30$ & Both \\
\hline M. Sadeghi [17] & 2003 & 12494 & - & + & $>20$ & Both \\
\hline L. Navaee [18] & 2002 & 2033 & + & + & $>30$ & Both \\
\hline M. Gharipour [19] & 2003 & 3694 & - & + & $19-64$ & Both \\
\hline N. Saadat [20] & 2002 & 9229 & + & + & $>20$ & Both \\
\hline A. Hoseinianamiri [21] & 2000 & 2755 & + & - & $>30$ & Both \\
\hline A. Barzigar [22] & 1996 & 2384 & + & - & $>30$ & Both \\
\hline
\end{tabular}

WHO $=$ World Health Organization; $A D A=$ American Diabetes Association. 


\begin{tabular}{|c|c|c|}
\hline Province & $\begin{array}{c}\text { Prevalence in the } \\
\text { Iranian Health Profile } \\
\text { Survey }\end{array}$ & $\begin{array}{c}\text { Prevalence in } \\
\text { individual studies }\end{array}$ \\
\hline & $\%(95 \% \mathrm{Cl})$ & $\%(95 \% \mathrm{Cl})$ \\
\hline Ardabil & $1.8(0-7.72)$ & - \\
\hline Bushehr & $2.0(0-8.48)$ & $\begin{array}{l}12.62(7.62-17.63) \\
12.58(7.47-17.69)\end{array}$ \\
\hline Chahar Mahall va Bakhtiari & $1.5(0-8.06)$ & - \\
\hline East Azarbaijan & $1.8(0-5.11)$ & - \\
\hline Fars & $2.0(0-5.23)$ & - \\
\hline Qazvin & $1.6(0-7.95)$ & 13.09 (7.93-18.25) \\
\hline Gilan & $2.1(0-6.2)$ & $5.45(1.78-9.13)$ \\
\hline Golestan & $3.1(0-8.17)$ & - \\
\hline Hamadan & $1.0(0-5.74)$ & - \\
\hline Hormozgan & $1.0(0-6.56)$ & - \\
\hline Ilam & $0.7(0-6.87)$ & - \\
\hline Isfahan & $2.3(0-5.45)$ & $\begin{array}{c}8.20(5.23-11.17) \\
12.19(6.67-17.72) \\
2.69(0.98-4.39)\end{array}$ \\
\hline Kerman & $1.8(0-6.24)$ & $13.16(7.55-18.77)$ \\
\hline Kermanshah & $1.7(0-6.33)$ & - \\
\hline Khuzestan & $2.2(0-5.37)$ & - \\
\hline Khorasan & $1.7(0-4.26)$ & 9.09 (2.28-15.89) \\
\hline Kohgiluyeh va Buyer & $0.6(0-6.82)$ & \\
\hline Kordestan & $1.3(0-6.89)$ & $3.35(0-7.36)$ \\
\hline Lorestan & & $3.62(0.14-7.10)$ \\
\hline Mazandaran & $3.2(0-7.38)$ & - \\
\hline Markazi & $1.9(0-7.64)$ & - \\
\hline Qom & $3.7(0-10.46)$ & - \\
\hline Semnan & $1.8(0-9.41)$ & - \\
\hline Sistan va Baluchestan & $0.7(0-5.34)$ & - \\
\hline Tehran & $4.1(2.27-5.93)$ & $\begin{array}{c}7.43(4.04-10.81) \\
6.12(4.17-8.06) \\
8.52(3.77-13.26) \\
6.39(2.47-10.31) \\
10.54(8.36-12.73) \\
23.82(19.9-27.73)\end{array}$ \\
\hline West Azarbaijan & $1.1(0-4.93)$ & - \\
\hline Yazd & $4.7(0-10.96)$ & $14.01(10.75-17.27)$ \\
\hline Zanjan & $1.3(0-7.71)$ & $4.62(0.61-8.63)$ \\
\hline Overall & $2.3(1.30-3.10)$ & $9.34(6.74-11.74)$ \\
\hline Heterogeneity test & $Q=7.5 ; P=0.94$ & $Q=172 ; P<0.001$ \\
\hline
\end{tabular}


2 categories (IHPS and individual studies) adjusted for other potential confounders, we entered the data in a meta-regression model. Based on the results, the difference in the crude estimates of the prevalence of type 2 diabetes in IHPS and individual studies (2.3\% versus $9.34 \%)$ decreased to $0.16 \%$, but this was not statistically significant $(P$ $=0.94)($ Table 3$)$. This means that the observed difference in the crude analysis was mainly due to a difference in the mean age of the subjects. Overall, the meta-regression results show that with each year increase in the mean age of subjects over 20 years old, the estimated prevalence increased $0.4 \%(P$ $=0.0001)$. The publication year, however, did not have any significant effect on the estimated prevalence (Table 3 ).

After weighting for sample size, the age-stratified prevalence of type 2 diabetes in subjects $>40$ years was computed at just over 24\% (Figure 1).

Only 13 studies reported the prevalence in females and males separately. Using their data, the weighted prevalence of type 2 diabetes was $9.84 \%$ in males and $10.68 \%$ in females $(P<0.001)$. The meta-regression analysis showed the estimated prevalence of type 2 diabetes in females at around 1.7\% greater than that of males $(P<0.0001)$.

\begin{tabular}{|c|c|c|c|}
\hline \multicolumn{4}{|c|}{$\begin{array}{l}\text { Table } 3 \text { Results of meta-regression model } \\
\text { assessing the effects of mean age of } \\
\text { subjects, publication year and the type of } \\
\text { study [individual studies versus the Iranian } \\
\text { Health Profile Survey (IHPS)] }\end{array}$} \\
\hline Variable & Coefficient & $\begin{array}{l}\text { Standard } \\
\text { error }\end{array}$ & $P$-value \\
\hline ige (years) & 0.40 & .09 & $<0.0001$ \\
\hline $\begin{array}{l}\text { ublication } \\
\text { date }\end{array}$ & 0.06 & 0.39 & 0.87 \\
\hline $\begin{array}{c}\text { ype of study } \\
\text { (IHPS as } \\
\text { baseline) }\end{array}$ & 0.16 & 1.98 & 0.94 \\
\hline
\end{tabular}

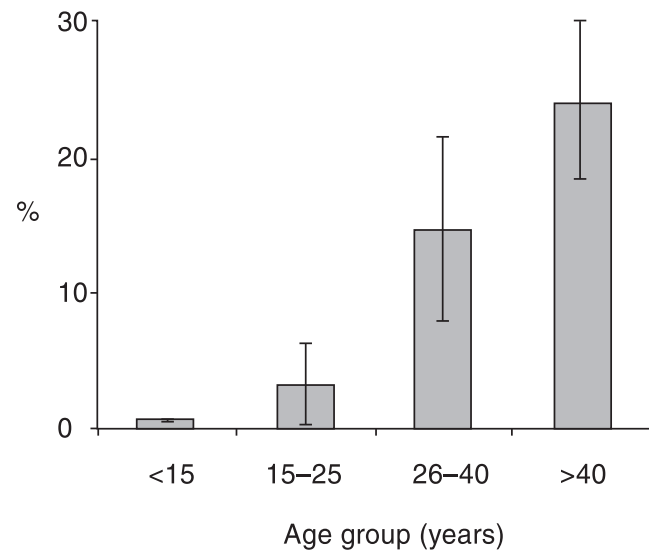

Figure1 Prevalence of type 2 diabetes in different age groups and their $95 \%$ confidence intervals (numbers weighted based on sample sizes of the studies)

However, there was considerable heterogeneity among the study findings $(\mathrm{Q}=129.3$, $P<0.0001$ ) (Figure 2).

\section{Discussion}

This meta-analysis provided evidence that the overall prevalence of type 2 diabetes in the Iranian population depends on age, and, after the age of 20 years, for each year increase in age, the prevalence increases around $0.4 \%$. In those over 40 years of age, our estimation of the prevalence was around $24 \%$. However, we did not find any explicit evidence that the prevalence varied significantly between 1996 and 2004 .

A wide range in prevalence of type 2 diabetes has been reported from around $3 \%$ up to $20 \%$ [23]. In northern parts of Sudan the prevalence of type 2 diabetes and impaired glucose tolerance (IGT) was 3.4\% and $2.9 \%$ respectively [24]. In 2005, Malik et al. reported prevalence of type 2 diabetes about $20 \%$, and prevalence of IGT about 


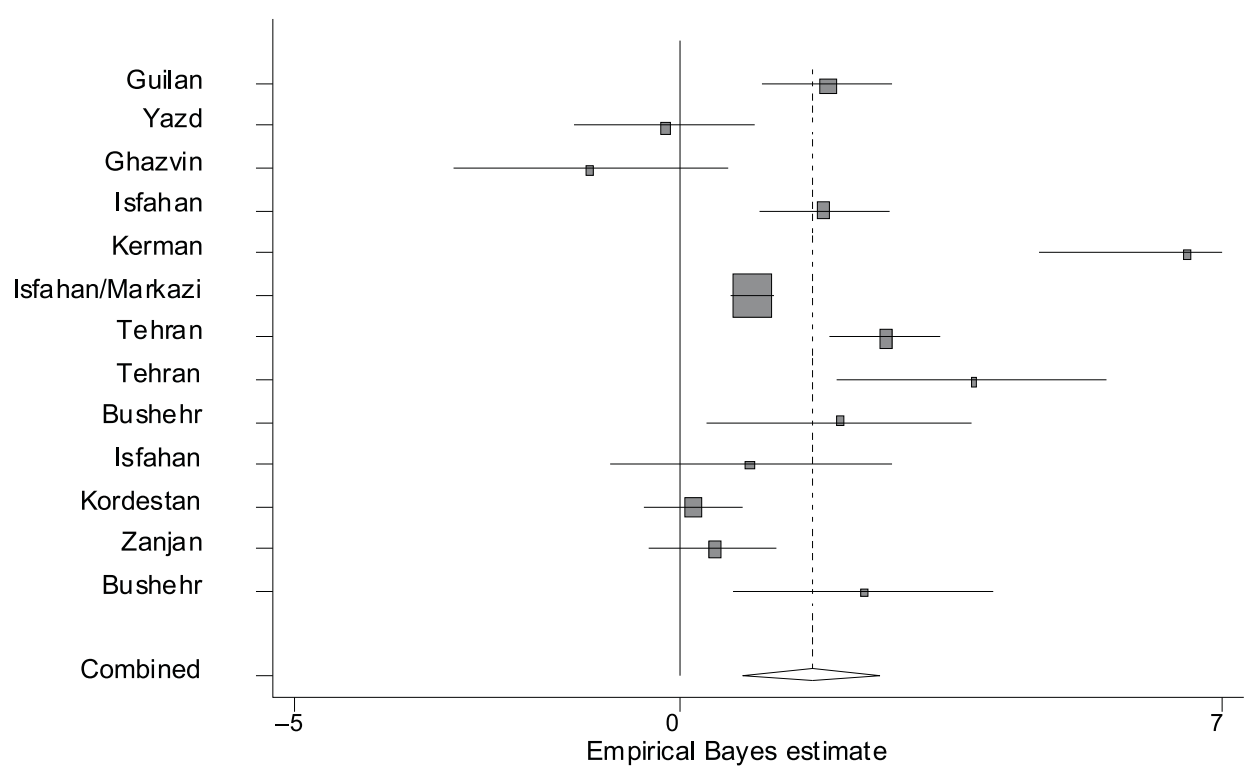

Figure 2 Difference between estimated prevalence of type 2 diabetes in each province

$5 \%$ in men and 7\% in women in the United Arab Emirates [25]. Musaiger reported a prevalence of $8.5 \%$ in Bahrain [26]. Ramachandran et al. reported a prevalence of $12.1 \%$ in an urban population of India, with prevalence of IGT 14\% [27,28].

Although the interpretation of the trend of diabetes over time in a country is difficult when different sample sizes were used, it seems that the prevalence of type 2 diabetes in the Islamic Republic of Iran is greater than the average prevalence in other developing countries. This may be because the samples in most of these studies were collected in a small area or one city, therefore the estimated prevalence could not be generalized. In addition, there is very strong evidence to show that type 2 diabetes is highly age-dependent. In other words, the estimated prevalence greatly depends on the age group of the sample. Therefore, even population-based sampling from com- munities with different age pyramids could show quite varied prevalence, even with similar risk of the condition. This issue is very important in explaining the difference in type 2 diabetes prevalence in developed and developing countries.

Based on the above explanations, we would suggest that meta-analysis and metaregression methods could adjust the data for important confounding factors such as age and thus help us to generate more reliable hypotheses about the time and location variations of type 2 diabetes between, and even within, countries.

In our analysis, the prevalence of type 2 diabetes in women was $1.7 \%$ higher than that in men in the Iranian population. Greater prevalence of type 2 diabetes in women has been reported in other studies as well [24-26]. Because of data limitations and also the risk of ecological fallacy, we could not assess the reasons for such a difference.

المجلة الصحية لشرق المتوسط، منظمة الصحة العالمية، المجلد الخامس عشر، العدد ؟، 9 + · 
However, greater body mass index among women and also their lifestyle are possible factors reported in other studies [29].

The main limitation of our study was that the estimated prevalence was not adjusted according to the size of the target population of each study. Obviously the results of a cluster analysis are more reliable, but conducting a large study with perfect cluster sampling at the national level is very difficult, costly and impractical. Therefore, it seems that meta-analysis is a more feasible alternative method.

\section{Conclusion}

We conclude that the rate of type 2 diabetes has increased in the Islamic Republic of
Iran and there is a strong association between age and diabetes. Also the findings show that the prevalence of type 2 diabetes is more common in women than men. Therefore it is recommended that Iranian health policy-makers initiate and launch more health promotional programmes and effective interventions.

\section{Acknowledgements}

This project was financially supported by Kerman University of Medical Sciences; we would like to acknowledge the contribution of the Deputy for Research. In addition, we thank those researchers who generated useful findings for our meta-analysis.

\section{References}

1. Economic consequences of diabetes mellitus in the US in 1997. Diabetes care, 1998, 21:296-309.

2. Amos AF, McCarty DJ, Zimmet P. The rising global burden of diabetes and its complications: Estimates and projections to the year 2010. Diabetic medicine, 1997, 14:S7-85.

3. ZimmetP.Globalization, coca-colonization and the chronic disease epidemic: can the doomsday scenario be averted? Journal of internal medicine, 2000, 247:301-10.

4. Sharifi HA, Azizi F. [Prevalence of diabetes and IGT in population older than 30 years in Zanjan province villages]. Pajoohesh dar Pezeshki [Research in medicine; Journal of Zanjan Medical School], 1999, 22(1):55-64 [In Farsi].

5. Larijani B. Prevalence of type 2 diabetes mellitus and IGT in 30-64 years old population of Booshehr city according to ADA and WHO criteria. Iranian journal of diabetes \& lipid disorders, 2002, 1(2):119-22.
6. Bastanhagh P, Larijani B, Sajadi F. [Comparison of the prevalence of type 2 diabetes in Bushehr and Tehran in urban population]. Abstract presented at the Iranian Endocrinology \& Metabolism National Conference, Tehran, 1996 [In Farsi].

7. Osfouri E et al. [Diabetes mellitus and impaired glucose tolerance (IGT) in 30-64 years old population of Booshehr Harbor]. Tebb-e-Jonoob [South medicine journal], 1998, 3(1):209-16 [In Farsi].

8. Sajadi $\mathrm{F}$ et al. [Prevalence of type II diabetes mellitus and its association with cardiovascular risk factors in Isfahan population]. Journal of Isfahan University of Medical Sciences, 2003, 46(81):68-73 [In Farsi].

9. Yazdanpanah K. [Prevalence of diabetes and its association with hypertension and obesity in population older than 10 years in Sanandaj]. Journal of Kordestan University of Medical Sciences, 2000 , 4(14):27-32 [In Farsi]. 
10. Afkhamiardakani M, Vahidi A, Ahmadieh M. [Evaluation of the epidemiologic indexes of adult diabetes mellitus in population older than 30 years in Yazd province, Iran]. Journal of Sadoghi [Yazd] University of Medical Sciences, 2002, 1:22-7 [In Farsi].

11. Jafarzadehfakhari M. [Obesity and cardiovascular risk factors]. Asrar (Journal of the Sabzevar University of Medical Sciences), 2000, 6(3):105-11 [In Farsi].

12. Azizi F. Cardiovascular risk factors in elderly population, Tehran Lipid and Glucose Study (TLGS). Iranian journal of endocrinology and metabolism, 2003 5(1):3-14.

13. Azizi $F$, Salehi $P$, Emami H. Relation of impaired glucose tolerance test with hypertension indexes, body mass index and waist hip rate in Tehran urban population. Iranian journal of endocrinology and metabolism, 2002, (4):247-56.

14. Fakhrzadeh $\mathrm{H}$ et al. Disorders of lipid and glucose metabolism in petroleum industry workers of Khark Island. Iranian journal of diabetes \& lipid disorders, 2002 1(2):123-31.

15. Larijani B et al. [Prevalence of diabetes mellitus and impaired glucose tolerance of population aged over 25 years in Quazvin]. Journal of Quazvin University of Medical Sciences, 2003, (26):41-5 [In Farsi].

16. Salem $Z$ et al. [Prevalence of type 2 diabetes mellitus of population over 30 years old in Rafsanjan]. Journal of Rafsanjan University of Medical Sciences, 2003, 3(1):9-16 [In Farsi].

17. Sadeghi $M$ et al. [Prevalence of high blood pressure and its relation with cardiovascular risk factors]. Journal of Qazvin University of Medical Sciences, 2003, 26:46-52 [In Farsi].

18. Navaee L, Lesankhoshnik R, Azizi F. [Comparison of fasting blood sugar and glucose tolerance test using $\mathrm{WHO}$ and ADA criteria in diagnosis of diabetes in Eslamshahr (suburb area of Tehran)]. Journal of Hammedan University of Medical Sciences, 2002, 9(3):26-30 [In Farsi].

19. Gharipour M, Asgary S, Naderi G. [The prevalence of obesity and cardiovascular risk factors in Isfahan]. Journal of Quazvin University of Medical Sciences, 2003, 26:53-64 [In Farsi].

20. Saadat N, Salehi $P$, Azizi F. Comparing ADA and $\mathrm{WHO}$ criteria in diagnosis of glucose metabolism disorders in Tehran urban Population. Iranian journal of endocrinology and metabolism, 2002, 4(1):1-8.

21. Hoseinianamiri A, Niknam H. [Determining the prevalence of diabetes in population older than 30 in Lorestan Province]. Tehran, Ministry of Health and Medical Education, 2000 [In Farsi].

22. Barzigar A et al. [Investigating the prevalence of diabetes mellitus in Some-eSara]. Abstract presented at the Iranian Endocrinology \& Metabolism National Conference, Tehran, 1996 [In Farsi].

23. Castro-Sánchez H, Escobedo de la Peña J. La prevalencia de la diabetes mellitus no dependiente de insulina y factores de riesgo asociados, en población mazateca del estado de Oaxaca, México [Prevalence of non insulin dependent diabetes mellitus and associated risk factors in the Mazatec population of the State of Oaxaca, Mexico]. Gaceta médica de México, 1997, 133(6):527-34.

24. Elbagir MN et al. A population-based study of the prevalence of diabetes and impaired glucose tolerance in adults in northern Sudan. Diabetes care, 1996 19(10):1126-8.

25. Malik M, Saab BA, King $H$. Glucose intolerance and associated factors in the multi-ethnic population of the United Arab Emirates: results of a national survey. 
Diabetes research and clinical practice, 2005, 69(2):188-95.

26. Musaiger AO. Diabetes mellitus in Bahrain: an overview. Diabetic medicine, 1992, 9(6):574-8.

27. Ramachandran A et al. Diabetes Epidemiology Study Group in India (DESI). High prevalence of diabetes and impaired glucose tolerance in India: National Urban Diabetes Survey. Diabetologia, 2001, 44(9):1094-101.
28. Ramachandran A. Epidemiology of diabetes in India-three decades of research. Journal of the Association of Physicians of India, 2005, 53:34-8.

29. Pan WH et al. Prevalence and awareness of diabetes and mean fasting glucose by age, sex, and region: results from the Nutrition and Health Survey in Taiwan, 1993-1996. Diabetic medicine, 2003, $20: 182-5$

\section{Diabetes in the Eastern Mediterranean Region}

It is predicted that between 2000 and 2025, there will be a $60 \%$ increase in diabetes in developing countries and more than $75 \%$ of the world's diabetic population will be living in developing countries.

In the Eastern Mediterranean Region, the diabetes prevalence rate for adults is $14.5 \%$. While the majority of persons with diabetes mellitus in industrialized countries are in the older age group, many Eastern Mediterranean countries are now reporting the onset of type 2 diabetes mellitus at an increasingly young age, in the second and third decade, and in some countries it is emerging in children. This pattern of onset at a younger age extends the potential burden of therapy and complications to an even younger age group and for a longer period of an individual's lifespan.

Source: WHO/EMRO Noncommunicable diseases website (http://www.emro.who.int/ncd/diabetes_emr.htm).

المجلة الصحية لشرق المتوسط، منظمة الصحة العالمية، المجلد الخامس عشر، العدد ؟، 9 + • 